Revista de

Contabilidade e

Organizações

www.rco.usp.br
DOI: http://dx.doi.org/10.11606/issn.1982-6486.rco.2019.145151

Journal of

Accounting and

Organizations

\title{
Os Tribunais de Contas na interpretação da Lei de Responsabilidade Fiscal
}

\section{The Courts of Accounts on the interpretation of the Fiscal Responsibility Law}

Selene Peres Peres Nunes ${ }^{\text {a }}$ Gileno Fernandez Marcelino ${ }^{a}$; César Augusto Tibúrcio Silva ${ }^{a}$

${ }^{a}$ Universidade de Brasília

Palavras-chave

Instituições.

Mudança institucional.

Tribunais de Contas.

Lei de Responsabilidade Fiscal.

Contabilidade Criativa.

\section{Resumo}

O trabalho analisa as interpretações dadas à Lei de Responsabilidade Fiscal nos 19 anos de sua implantação. Como uma instituição que procura regular a gestão fiscal de governos por todo o País, parte significativa da coerção da Lei no nível regional e local cabe aos Tribunais de Contas de Estados e Municípios. Adotou-se o modelo teórico de mudança institucional de Mahoney e Thelen (2009), com evidências coletadas por questionário, para dar uma primeira explicação para a mudança incremental na legislação fiscal. A Lei de Responsabilidade Fiscal tem sido interpretada pelos órgãos de auditoria, de tal forma que, em alguns casos, surgem práticas de contabilidade criativa, diminuindo a contenção do gasto excessivo e gerando sobre-endividamento.
Keywords

Institutions.

Institutional change.

Courts of Accounts.

Fiscal Responsibility Law.

Creative Accounting.

\begin{abstract}
The paper analyzes the interpretations given to the Fiscal Responsibility Law after 19 years of its implementation. As an institution that seeks to regulate the fiscal management of governments throughout the country, a significant part of the enforcement of the law at the regional and local level rests with the State and Municipal Courts of Accounts. We adopted the theoretical model of institutional change by Mahoney and Thelen (2009), with evidence collected by questionnaire, to give a first explanation for the incremental change of such fiscal legislation. The Fiscal Responsibility Law has been interpreted by the auditing bodies, in such a way that, in some cases, creative accounting practices emerge, reducing the containment of excessive spending and generating over-indebtedness.
\end{abstract}

Informações do Artigo

Recebido: 09 de abril de 2018

Aceito: 14 de dezembro de 2018

Publicado: 26 de abril de 2019

\section{Implicações práticas}

A discussão interessa a gestores públicos, parlamentares, observatórios sociais e membros dos Tribunais de Contas para a reflexão dos impactos das suas práticas na gestão fiscal de estados e municípios. Jornalistas especializados em Finanças Públicas e questões orçamentárias, podem se interessar nas razões pelas quais diversos critérios e interpretações são adotados em diferentes estados, gerando diferentes níveis de responsabilidade fiscal na Federação.

Copyright $@ 2019$ FEA-RP/USP. Todos os direitos reservados

\section{INTRODUÇÃO}

Desde a introdução da Lei Complementar $n^{\circ}$ 101/2000, chamada de Lei de Responsabilidade Fiscal (LRF), em 2000, têm sido constatadas várias mudanças institucionais dadas pela interpretação da legislação pelos Tribunais de Contas (TCs), ocasionando uma espécie de mutação genética. Embora isso não gere um problema de compliance para governadores e prefeitos no curto prazo, porque cumprem as normas dos tribunais de contas, pode inviabilizar a gestão financeira no médio prazo e certamente reduzir a uniformidade da regulação fiscal na Federação.

Autor Correspondente: Tel. (61) 99973-1376

E-mail: selenenunes@gmail.com (S. P. P. Nunes); gileno.marcelino@gmail.com (G. F. Marcelino); cesaraugustotiburciosilva@gmail.com (C. A. T. Silva)

Universidade de Brasília. Campus Universitário Darcy Ribeiro, - qd-606 qd-607 - Asa Norte, Brasília/DF - 70910-900, Brasil. 
Consequentemente, o comportamento de governos estaduais e municipais, assim como comissões de orçamento e finanças das casas legislativas, não é o mesmo entre os diversos estados. Tal fato tem contribuído para a redução da capacidade da regra fiscal de controlar o gasto excessivo e sobre-endividamento de governos.

Quando uma legislação é proposta e aprovada, enquanto instituição formal, passa a operar com o objetivo de direcionar comportamentos e escolhas, em um ambiente já permeado por inúmeras outras instituições preexistentes. No caso em questão, a aprovação da LRF, em 2000, passou a ser operacionalizada pelos Tribunais de Contas, que tinham então o mandato legal para exercer o controle externo sobre governos estaduais e municipais. A nova lei trouxe aos Tribunais de Contas uma ampliação das suas competências e poder, ao criar novas hipóteses para reprovação de contas com base nos seus julgamentos e decisões.

Uma vasta literatura empírica publicada em periódicos no Brasil discute os impactos da LRF nas Finanças Públicas, chegando a resultados positivos sobre o cumprimento de limites de dívida após a sua introdução, como Santos (2005), Giambiagi e Mora (2007) e Cruz e Afonso (2018). Outros estudos mostram o descontrole fiscal, com o aumento da dívida dos quatro maiores estados (Ferreira Júnior, 2006) e dos restos a pagar (Aquino \& Azevedo, 2017). Contudo, em geral, os estudos empíricos tratam a LRF como se fosse uma única instituição e ignoram a interpretação dos Tribunais de Contas. Raras exceções são Santiso (2009) e Hidalgo et al. (2016).

Contudo, cada um dos mais de trinta Tribunais de Contas estaduais e municipais no Brasil tem suas resoluções e entendimentos específicos sobre a forma de operacionalizar a LRF e normas associadas. O mandato legal dos Tribunais de Contas lhes permite alguma discricionariedade na interpretação e operacionalização da LRF para seus jurisdicionados. Essa potencial discricionariedade já foi apontada por Lino e Aquino (2018), Azevedo e Lino (2018) e Loureiro et al. (2009). Essa discricionariedade chega a ser tal que suscita a criação de um Conselho Nacional dos Tribunais de Contas ${ }^{1}$ ou do Conselho de Gestão Fiscal ${ }^{2}$ previsto na LRF para reduzir divergências, embora haja risco de que os tribunais de contas não sujeitem suas interpretações a essas instâncias ou exerçam nelas, via representação, pressão política para reinterpretar a LRF, convalidando e estendendo a todos os estados as práticas de alguns.

A mudança na LRF pela diversificação de sua interpretação é tratada aqui como um caso de mudança institucional incremental. Para analisar o fenômeno, adota-se o modelo de Mahoney e Thelen (2009), não necessariamente para dar uma explicação definitiva para o processo de mudança institucional, mas como um pano de fundo para tipificar as diversas interpretações que surgiram para pontos específicos da LRF e seus possíveis impactos fiscais nos governos.

O modelo de Mahoney e Thelen (2009) é apresentado na seção de literatura, na qual os autores reúnem três escolas institucionais, e mudam a perspectiva de análise com foco na estabilidade e persistência, para a mudança incremental, não motivada por choques externos, mas pela distribuição de poder e recursos dos atores envolvidos. No caso da LRF, Tribunais de Contas, Casas Legislativas, Prefeituras e Governos de Estados têm papel central na dinâmica dos últimos 19 anos. O mandato legal dos Tribunais de Contas cria espaço para interpretar a LRF, propor métricas, formas de cálculo de limites fiscais, manuais e procedimentos a serem seguidos por seus jurisdicionados, determinando o grau de cumprimento da Lei.

Adotou-se uma abordagem qualitativa, de múltiplos casos. O questionário, que aborda as interpretações dadas a certos parâmetros da LRF, foi enviado a auditores de controle externo de todos Tribunais de Contas. Foram recebidas respostas de auditores de 12 Tribunais de Contas. Com estas respostas, observou-se a variação das interpretações nos casos em questão.

\section{MUDANÇA INSTITUCIONAL INCREMENTAL}

O modelo de Mahoney e Thelen (2009) teoriza sobre a possibilidade de mudança incremental, usualmente negligenciada na maioria das análises institucionalistas (sociológica, de escolha racional e histórica). Nestas últimas, o foco de análise é a mudança radical por choques exógenos que rompem a inércia da continuidade de instituições dependentes de trajetória (path dependency).

\footnotetext{
${ }^{1}$ As Propostas de Emenda Constitucional no 28/2007, 146/2007 e 22/2017 tratam da criação de um Conselho Nacional de Tribunais de Contas. Solução diferente é prevista pela PEC 389/2013, que altera a forma de composição dos TCs, restringindo o espaço para indicação política dos seus membros. Nesse modelo, a fiscalização dos deveres funcionais dos membros dos TCs ficaria a cargo do Conselho Nacional de Justiça e a competência para uniformização de entendimentos seria do Tribunal de Contas da União, sem necessidade de criação de um Conselho Nacional de Tribunais de Contas.

${ }^{2} \mathrm{O}$ funcionamento do Conselho de Gestão Fiscal é proposto pelo Projeto de Lei no 3744/00.
} 
Na mudança incremental, o pressuposto é que a força motriz da mudança não é necessariamente exógena, mas decorre das relações de poder entre os agentes que, no processo de adaptação e aprendizado institucional, podem reinterpretar as regras. Embora as instituições representem compromissos duradouros, garantir a continuidade das mesmas requer a mobilização contínua de apoio político. Se as dinâmicas de coalizão mudam, as instituições podem ser contestadas e tornam-se vulneráveis a mudanças. Quando o grupo que interpreta as regras é dominante, pode fazer com que a interpretação das regras corresponda às suas preferências; porém, se houver conflito entre grupos, o resultado não intencional poderá ser um compromisso ambíguo, dada a composição de forças.

A teoria de Mahoney e Thelen (2009) fornece subsídios para a compreensão do processo histórico de mudança institucional, mostrando que as mudanças não acontecem apenas pela via legislativa e em momentos de crise, mas em longos períodos de estabilidade política e organizacional, pela via interpretativa. A taxonomia inclui quatro tipos de mudança institucional (Quadro 1). No deslocamento (displacement), ocorre a remoção e introdução de novas regras, após uma disputa. Mas a mudança também pode acontecer por acréscimo em camadas (layering), em que novas regras são adicionadas às antigas, mudando o impacto das regras originais no comportamento dos indivíduos. Pode ocorrer também o deslizamento (drift), em que as regras continuam as mesmas, mas seu impacto muda devido a alterações no contexto/ambiente. Por fim, pode correr uma conversão (conversion), em que as regras continuam formalmente as mesmas, mas são interpretadas e aplicadas de maneiras diferentes.

Na mudança gradual, os atores desempenham papel relevante e a sua capacidade de veto às mudanças, bem como o nível de arbítrio na interpretação, podem fazer com que as regras continuem formalmente as mesmas, embora sejam interpretadas e aplicadas de maneiras diferentes. As características das instituições e do contexto político são determinantes para explicar que tipo de mudança ocorrerá. Se a instituição é mais rígida e, por sua natureza, não permite interpretações ou variação do grau de enforcement, como uma regra formal, o mais provável é que os agentes se mobilizem para alterar a regra no Legislativo.

Se essa mudança será ou não factível, é algo que dependerá do poder de veto dos agentes. Se têm maior poder, podem gerar acréscimos em camadas, como ocorre quando uma lei passa por várias alterações legislativas que vão, aos poucos, mudando a regra original. Se têm menos poder nas circunstâncias específicas, a regra pode ser inteiramente substituída por outra, o que frequentemente ocorre quando crises geram janelas de oportunidade para reformas no Legislativo (criação de lei, alteração da Constituição). Os agentes com baixo poder de veto seriam "perdedores" do jogo anterior à nova instituição criada.

Se, por outro lado, as características da instituição (ou do próprio sistema jurídico em que ela se insere) permitem discricionariedade na interpretação ou no enforcement com que é aplicada e os agentes têm maior poder de veto, é provável que ocorra o deslizamento, em que a instituição permanece formalmente a mesma, mas, na prática, é negligenciada. Os agentes são fortes o bastante para negligenciarem sem serem punidos. Se, contudo, têm baixo poder de veto, podem fazer conversão, alterando na margem as interpretações da lei, de modo a permitirem um cumprimento artificial. Desse modo, diferentes estratégias florescem a depender do contexto, das características das regras em si e dos atores que as operam. Nada é automático e tais mudanças são endógenas.

\begin{tabular}{cccc}
\hline & & \multicolumn{2}{c}{ Características das instituições alvo } \\
\hline & $\begin{array}{c}\text { Baixo nível de discricionariedade } \\
\text { na interpretação / enforcement }\end{array}$ & $\begin{array}{c}\text { Alto nível de discricionariedade } \\
\text { na interpretação / enforcement }\end{array}$ \\
$\begin{array}{c}\text { Características do } \\
\text { contexto político } \\
\text { de veto }\end{array}$ & $\begin{array}{c}\text { Acréscimo em camadas } \\
\text { Baixo poder } \\
\text { de veto }\end{array}$ & Deslocamento & Deslizamento \\
\hline
\end{tabular}

Quadro 1. Fontes de mudança institucional

Fonte: Mahoney e Thelen (2009), tradução livre.

Há vários exemplos de trabalhos que já empregaram esse modelo na análise de políticas públicas específicas no Brasil: Rodrigues (2011) analisou a conversão institucional na reforma da segurança pública, enquanto Castro e Machado (2012) e Grin (2014) avaliaram o acréscimo em camadas (layering), respectivamente, na política federal de atenção básica à saúde e nos programas federais voltados a promover a eficiência administrativa e fiscal dos municípios. Nenhum dos trabalhos tratou especificamente da LRF, nem observou o papel dos tribunais de contas na mudança institucional via conversão. 


\section{METODOLOGIA}

Adotou-se uma abordagem qualitativa, com coleta de dados de documentos como legislação aplicada, relatórios do Programa de Modernização do Controle Externo dos Estados e Municípios Brasileiros (Promoex), bem como alguns Acórdãos, Resoluções e Relatórios Técnicos de TCs e levantamento do Superior Tribunal de Justiça. Foi aplicado um questionário aberto junto aos técnicos dos TCs para captar as diferenças nas regras de composição e funcionamento dos TCs e também eventuais práticas de cálculo que poderiam configurar certa flexibilização na aplicação da LRF. O questionário é apresentado no Apêndice A. Na primeira parte, foi perguntado sobre as regras de composição e funcionamento dos TCs, e na segunda sobre interpretações do texto original da LRF, que surgem nas análises técnicas e decisões daquelas Cortes.

Dos 34 TCs existentes, trabalhou-se com uma amostra de 12. Foram ouvidas 19 pessoas, todos Procuradores do Ministério Público de Contas ou técnicos exercendo funções de fiscalização e auditoria, especialmente no que se refere à LRF. As respostas foram sistematizadas, procurando-se identificar os pontos de convergência. As respostas a perguntas abertas foram selecionadas pela capacidade de explicar o que era perguntado. Por se tratar de temas sensíveis, foi preciso assumir um compromisso com os respondentes de que eles não seriam identificados, o que foi observado ao sistematizar as respostas.

As perguntas sobre interpretações do texto original da LRF, foram baseadas na experiência profissional da autora, que há 21 anos atua na questão, participando na elaboração original da LRF, e ao longo de 19 anos acompanhando a regulamentação e a tentativa de harmonização de procedimentos na Federação brasileira. Ao longo da experiência da autora, coletou-se evidências em notícias de jornais, pareceres técnicos e relatórios de reuniões de que participaram técnicos dos TCs, de que a LRF sofre mudança na interpretação no mínimo em 5 temas particulares: (i) limite de Despesas com pessoal/Receita Corrente Líquida, (ii) limite de Dívida Consolidada Líquida/Receita Corrente Líquida, (iii) Renúncia de Receita, (iv) Restos a pagar, (v) Metas fiscais.

Estes temas estão apresentados na Tabela 1, com as respectivas questões correspondentes no questionário aplicado (Apêndice A). Cada uma delas pode ter a rigidez original relaxada (na quase totalidade dos casos), ou intensificada. A Tabela 1 mostra, para cada tema, como a interpretação do TC pode afetar a rigidez da lei e beneficiar os jurisdicionados, o que pode ser feito pela edição de uma Resolução aplicável a todos os jurisdicionados, pela decisão em julgamento de caso concreto específico (não necessariamente se aplica a todos, permitindo decisões diferentes conforme o caso) ou simplesmente porque o TC não fiscaliza o tema rotineiramente. Uma das formas de relaxamento é a aplicação de limites retirando certos itens do cálculo. Mesmo que a exclusão seja feita no numerador e no denominador de um índice de limite fiscal, o efeito final é de relaxamento.

Há também casos em que os objetivos são conflitantes, por exemplo, quando se deseja aumentar a renúncia de receita e surge um efeito indesejável de queda da receita corrente líquida, o que motiva a adoção de relaxamentos adicionais na despesa com pessoal. A redução da transparência da questão normalmente acompanha tais interpretações.

A maioria das interpretações empreendidas pelos TCs relaxam a aplicação da LRF para jurisdicionados; em outros casos, porém, observa-se uma intensificação e fica claro que se trata de entendimento divergente, ou seja, o critério é adotado porque os TCs entendem que tal interpretação é correta, por razões puramente técnicas, como é o caso da exclusão de royalties da Receita Corrente Líquida.

A análise foi feita segundo uma abordagem comparada do tipo within-case (Ayres et al., 2003), focando observar os padrões de interpretação que aparecem nos casos analisados. As respostas dos 12 casos podem ser vistas na Tabela 2 a seguir. A identificação dos Tribunais de Contas, assim como dos técnicos que responderam as questões foi omitida para preservar a identidade dos respondentes. O objetivo em questão não é apontar a operação de cada TC, mas sim destacar a diferença de interpretação e as formas que são adotadas neste processo de interpretação. 
Tabela 1. Mudanças de Interpretação da LRF em 19 anos

\begin{tabular}{|c|c|c|c|}
\hline Tema & Questões & Como é relaxada (R) ou intensificada (I) a regra? & Meio para interpretação ou coerção \\
\hline \multirow{10}{*}{$\begin{array}{l}\text { Limite: } \\
\text { Despesas com pessoal } \\
\text { Receita Corrente Líquida }\end{array}$} & Imposto de Renda Retido na Fonte & $\begin{array}{l}\text { Exclusão da Receita Corrente Líquida, juntamente com a } \\
\text { exclusão na Despesa com Pessoal (R) }\end{array}$ & Resolução do TC \\
\hline & Inativos & $\begin{array}{l}\text { Exclusão das Despesas com pessoal (R) } \\
\text { Dedução das Despesas com pessoal do aporte para } \\
\text { cobertura de déficit financeiro dos fundos de previdência } \\
\text { (não admitido legalmente), simulando que é aporte atuarial } \\
\text { (admitido legalmente): "banho na Previdência" (R) }\end{array}$ & Julgamento de caso concreto \\
\hline & Pensionistas & Exclusão das Despesas com pessoal (R) & Resolução do TC \\
\hline & Distribuição de limites por Poder & Alteração dos limites: "condomínio de limites" (R) & $\begin{array}{l}\text { Lei de Diretrizes Orçamentárias (LDO) ou } \\
\text { Resolução do TC }\end{array}$ \\
\hline & $\begin{array}{l}\text { Despesas com Pessoal relativas ao Programa de Saúde } \\
\text { na Família }\end{array}$ & Exclusão das Despesas com pessoal (R) & $\begin{array}{l}\text { Resolução do TC ou julgamento de caso } \\
\text { concreto }\end{array}$ \\
\hline & $\begin{array}{l}\text { Espécies de despesas com caráter remuneratório. Ex: } \\
\text { auxílio-livro }\end{array}$ & $\begin{array}{l}\text { Exclusão das Despesas com pessoal, simulando que são } \\
\text { espécies indenizatórias (R) }\end{array}$ & Julgamento de caso concreto ou não atuação \\
\hline & $\begin{array}{l}\text { Realização de despesas "fora" do serviço público, } \\
\text { inclusive com burla ao concurso público }\end{array}$ & $\begin{array}{l}\text { Exclusão das Despesas com pessoal: "burla de abrangência" } \\
\text { (R) }\end{array}$ & $\begin{array}{l}\text { Em alguns casos houve atuação do TC, em } \\
\text { outros não }\end{array}$ \\
\hline & Royalties & Exclusão da Receita Corrente Líquida (I) & $\begin{array}{l}\text { Resolução do TC ou julgamento de caso } \\
\text { concreto }\end{array}$ \\
\hline & $\begin{array}{l}\text { Receitas vinculadas (transferências voluntárias, por } \\
\text { exemplo) }\end{array}$ & Exclusão (I) & $\begin{array}{l}\text { Resolução do TC ou julgamento de caso } \\
\text { concreto }\end{array}$ \\
\hline & $\begin{array}{l}\text { Concessão do direito de exploração da folha de } \\
\text { pagamentos }\end{array}$ & Exclusão (I) & - \\
\hline \multirow{4}{*}{$\begin{array}{l}\text { Limite: } \\
\text { Dívida Consolidada Líquida } \\
\text { Receita Corrente Líquida }\end{array}$} & Ativos de baixa liquidez como Dívida Ativa & $\begin{array}{l}\text { Inclusão na Disponibilidade de Caixa que é deduzida da } \\
\text { Dívida Consolidada (R) }\end{array}$ & Não atuação do TC \\
\hline & Precatórios & Não registro na Dívida Consolidada (R) & Não atuação do TC \\
\hline & $\begin{array}{l}\text { Operação de Crédito com derivativos financeiros } \\
\text { (antecipações de royalties, dívida ativa, FIDC, etc.) ou } \\
\text { com antecipação de recebimentos ou postergação de } \\
\text { pagamentos. }\end{array}$ & $\begin{array}{l}\text { Realização de Operação de Crédito sem autorização da STN } \\
\text { e consequente exclusão do limite de Operações de Crédito e } \\
\text { da Dívida Consolidada (R) }\end{array}$ & Não atuação do TC \\
\hline & Ações trabalhistas em curso & Inclusão na Dívida Consolidada (I) & Não atuação do TC \\
\hline
\end{tabular}


Tabela 1. Mudanças de Interpretação da LRF em 19 anos (continuação)

\begin{tabular}{|c|c|c|c|}
\hline Tema & Questões & Como é relaxada (R) ou intensificada (I) a regra? & Meio para interpretação ou coerção \\
\hline \multirow[t]{2}{*}{ Renúncia de Receita } & $\begin{array}{l}\text { Fundos de receita (fundos de desenvolvimento, de } \\
\text { pobreza, etc.) }\end{array}$ & $\begin{array}{l}\text { Criação de fundos de receita para disfarçar a renúncia (R), } \\
\text { com efeito indesejável de exclusão da Receita Corrente } \\
\text { Líquida (I), compensado de outras formas }\end{array}$ & $\begin{array}{l}\text { Não atuação do TC ou julgamento de caso } \\
\text { concreto }\end{array}$ \\
\hline & $\begin{array}{l}\text { Utilização de fontes de compensação inadequadas } \\
\text { (crescimento econômico, por exemplo) }\end{array}$ & Omissão de informações em relatórios $(\mathrm{R})$ & $\begin{array}{l}\text { Não atuação do TC ou julgamento de caso } \\
\text { concreto }\end{array}$ \\
\hline \multirow{3}{*}{ Restos a pagar } & \multirow{2}{*}{$\begin{array}{l}\text { Despesas, inclusive liquidadas, dos restos a pagar } \\
\text { correspondentes }\end{array}$} & Exclusão/cancelamento (R) & $\begin{array}{l}\text { Em geral, houve atuação do TC, inclusive com } \\
\text { Resolução e julgamento de caso concreto }\end{array}$ \\
\hline & & $\begin{array}{l}\text { Alteração do sistema informatizado para impedir o registro } \\
\text { de despesas }(\mathrm{R})\end{array}$ & $\begin{array}{l}\text { Em geral, houve atuação do TC, inclusive com } \\
\text { Resolução e julgamento de caso concreto }\end{array}$ \\
\hline & Receitas por competência na Disponibilidade de Caixa & Inclusão (R) & $\begin{array}{l}\text { Em geral, houve atuação do TC, inclusive com } \\
\text { Resolução e julgamento de caso concreto }\end{array}$ \\
\hline \multirow{5}{*}{ Metas fiscais } & Ordem de credores/ período de cálculo & Inversão/exclusão (R) & $\begin{array}{l}\text { Em geral, houve atuação do TC, inclusive com } \\
\text { Resolução e julgamento de caso concreto }\end{array}$ \\
\hline & Parâmetros da LDO & Utilização de parâmetros irrealistas $(\mathrm{R})$ & Não atuação do TC \\
\hline & Conceito de ente da Federação & $\begin{array}{l}\text { Adoção de conceito diferente da LRF e instável, ora } \\
\text { incluindo, ora excluindo empresas estatais (R) }\end{array}$ & $\begin{array}{l}\text { Em alguns casos houve atuação do TC, em } \\
\text { outros não }\end{array}$ \\
\hline & $\begin{array}{l}\text { Limitação de empenho e movimentação financeira } \\
\text { (Contingenciamento) }\end{array}$ & Não contingenciar quando seria obrigatório $(\mathrm{R})$ & Não atuação do TC \\
\hline & Registro inoportuno de despesas & $\begin{array}{l}\text { Contratos de gaveta e realização de despesas sem } \\
\text { autorização orçamentária com posterior cobertura sob a } \\
\text { forma de Despesas de Exercícios Anteriores }(\mathrm{R})\end{array}$ & $\begin{array}{l}\text { Em alguns casos houve atuação do TC, em } \\
\text { outros não }\end{array}$ \\
\hline
\end{tabular}

Fonte: Elaboração própria. R: relaxamento; I: intensificação. 
Tabela 2. As interpretações dos Tribunal de Contas (descrição completa das 18 questões no Apêndice A)

\begin{tabular}{|c|c|c|c|c|c|c|c|c|c|c|c|c|}
\hline Caso & 1 & 2 & 3 & 4 & 5 & 6 & 7 & 8 & 9 & 10 & 11 & 12 \\
\hline Jurisdicionado único $(\mathrm{U})$ ou múltiplos $(\mathrm{M}) ?^{*}$ & M & $\mathrm{U}$ & M & M & $\mathrm{M}$ & $\mathrm{M}$ & $\mathrm{U}$ & M & M & M & $\mathrm{M}$ & $\mathrm{M}$ \\
\hline Região do país em que opera o TC & $\mathrm{N}$ & $\mathrm{N}$ & $\mathrm{N}$ & $\mathrm{N}$ & $\mathrm{NE}$ & NE & $\mathrm{CO}$ & $\mathrm{CO}$ & SE & SE & $\mathrm{S}$ & $\mathrm{S}$ \\
\hline Questão 1: LRF melhorou efetivamente a atuação do TC no controle? & SF/SI & SF/SI & SF/SI & $\mathrm{SF} / \mathrm{SI}$ & SF & SF/SI & SI & SF/SI & SF & SF/SI & SF & $\mathrm{SF} / \mathrm{SI}$ \\
\hline Questão 2: admite exclusões da receita corrente líquida & $\mathrm{n}$ & $\mathrm{n}$ & $\mathrm{n}$ & SF & $\mathrm{n}$ & $\mathrm{n}$ & $\mathrm{n}$ & - & $\mathrm{n}$ & $\mathrm{n}$ & $\mathrm{n}$ & $\mathrm{n}$ \\
\hline Questão 3: aceita \% de limites de pessoal diferentes da LRF & $\mathrm{n}$ & $\mathrm{n}$ & SI & $\mathrm{n}$ & $\mathrm{n}$ & $\mathrm{n}$ & $\mathrm{n}$ & $\mathrm{n}$ & $\mathrm{n}$ & $\mathrm{n}$ & $\mathrm{n}$ & $\mathrm{n}$ \\
\hline Questão 4: admite exclusões das despesas com pessoal não previstas na LRF & $\mathrm{n}$ & SF & $\mathrm{n}$ & $\mathrm{n}$ & SF & $\mathrm{n}$ & $\mathrm{n}$ & - & SI & SF & $\mathrm{n}$ & SI \\
\hline Questão 5: admite transferências de receitas e despesas previdenciárias & $\mathrm{n}$ & $\mathrm{n}$ & $\mathrm{n}$ & $\mathrm{n}$ & $\mathrm{n}$ & $\mathrm{n}$ & $\mathrm{n}$ & $\mathrm{n}$ & $\mathrm{n}$ & $\mathrm{n}$ & $\mathrm{n}$ & $\mathrm{n}$ \\
\hline Questão 6: admite aporte atuarial para cobrir déficit financeiro & $\mathrm{n}$ & $\mathrm{n}$ & $\mathrm{n}$ & SI & - & $\mathrm{n}$ & $\mathrm{n}$ & - & $\mathrm{n}$ & SI & $\mathrm{n}$ & $\mathrm{n}$ \\
\hline Questão 7: coíbe burla em concurso público & $\mathrm{n}$ & - & SI & $\mathrm{n}$ & SI & $\mathrm{n}$ & $\mathrm{n}$ & SI & SI & $\mathrm{n}$ & $\mathrm{n}$ & SI \\
\hline $\begin{array}{l}\text { Questão 8: admite atos de provimento pela alteração do sistema } \\
\text { remuneratório previsto no artigo } 39, \S 1^{\circ} \text { da Constituição Federal ('trem da } \\
\text { alegria') }\end{array}$ & SI & - & $\mathrm{n}$ & $\mathrm{n}$ & SI & SI & SI & - & $\mathrm{n}$ & $\mathrm{n}$ & $\mathrm{n}$ & $\mathrm{n}$ \\
\hline $\begin{array}{l}\text { Questão 9: admite o não uso do regime de competência para limites de } \\
\text { pessoal }\end{array}$ & $\mathrm{n}$ & $\mathrm{n}$ & SI & $\mathrm{n}$ & $\mathrm{n}$ & $\mathrm{n}$ & SI & $\mathrm{n}$ & $\mathrm{n}$ & SF & $\mathrm{n}$ & $\mathrm{n}$ \\
\hline Questão 10: admite abertura de créditos adicionais sem autorização legislativa & $\mathrm{n}$ & $\mathrm{n}$ & SI & $\mathrm{n}$ & $\mathrm{n}$ & $\mathrm{n}$ & $\mathrm{n}$ & $\mathrm{n}$ & $\mathrm{n}$ & $\mathrm{n}$ & $\mathrm{n}$ & $\mathrm{n}$ \\
\hline $\begin{array}{l}\text { Questão 11: admite o não contingenciamento necessário para cumprir metas } \\
\text { fiscais }\end{array}$ & SI & - & $\mathrm{D}$ & $\mathrm{n}$ & $\mathrm{D}$ & SI & SI & - & $\mathrm{n}$ & $\mathrm{n}$ & $\mathrm{n}$ & SI \\
\hline Questão 12: admite o não uso do regime de competência para despesas & SI & $\mathrm{n}$ & SI & $\mathrm{n}$ & $\mathrm{n}$ & $\mathrm{n}$ & $\mathrm{n}$ & - & $\mathrm{n}$ & $\mathrm{n}$ & $\mathrm{n}$ & SI \\
\hline $\begin{array}{l}\text { Questão 13: admite a exclusão de parcelas sem liquidez imediata no cálculo } \\
\text { da Dívida Consolidada Líquida }\end{array}$ & $\mathrm{n}$ & $\mathrm{n}$ & $\mathrm{D}$ & SI & $\mathrm{n}$ & - & - & - & $\mathrm{n}$ & $\mathrm{n}$ & $\mathrm{n}$ & $\mathrm{n}$ \\
\hline Questão 14: admite que passivos não sejam contabilizados & SI & $\mathrm{n}$ & $\mathrm{D}$ & $\mathrm{n}$ & SF & $\mathrm{n}$ & $\mathrm{D}$ & $\mathrm{n}$ & $\mathrm{n}$ & SI & $\mathrm{n}$ & $\mathrm{n}$ \\
\hline $\begin{array}{l}\text { Questão 15: aceita que, no final do mandato, os Restos a Pagar superem a } \\
\text { disponibilidade de caixa }\end{array}$ & $\mathrm{n}$ & $\mathrm{n}$ & SI & $\mathrm{n}$ & $\mathrm{n}$ & $\mathrm{n}$ & SI & $\mathrm{n}$ & $\mathrm{n}$ & $\mathrm{n}$ & $\mathrm{n}$ & $\mathrm{n}$ \\
\hline $\begin{array}{l}\text { Questão 16: aceita que, no final do mandato, os Restos a Pagar processados } \\
\text { sejam cancelados para que seja cumprido o limite de restos a pagar }\end{array}$ & $\mathrm{n}$ & $\mathrm{n}$ & SI & $\mathrm{n}$ & $\mathrm{n}$ & $\mathrm{n}$ & SI & $\mathrm{n}$ & $\mathrm{n}$ & $\mathrm{n}$ & $\mathrm{n}$ & SI \\
\hline $\begin{array}{l}\text { Questão 17: admite que seja utilizada a disponibilidade de caixa do exercício } \\
\text { seguinte (de janeiro, por exemplo) para calcular o limite dos restos a pagar }\end{array}$ & $\mathrm{n}$ & $\mathrm{n}$ & SI & $\mathrm{n}$ & $\mathrm{n}$ & $\mathrm{n}$ & - & - & $\mathrm{n}$ & $\mathrm{n}$ & $\mathrm{n}$ & SI \\
\hline $\begin{array}{l}\text { Questão 18: admite a falta de informações exigidas pela LRF em portal de } \\
\text { transparência }\end{array}$ & $\mathrm{n}$ & $\mathrm{n}$ & $\mathrm{n}$ & $\mathrm{n}$ & $\mathrm{D}$ & $\mathrm{n}$ & $\mathrm{D}$ & $\mathrm{n}$ & $\mathrm{n}$ & $\mathrm{n}$ & $\mathrm{n}$ & $\mathrm{n}$ \\
\hline
\end{tabular}

Fonte: Elaboração própria.

Nota: *Classificação segundo Lino e Aquino (2018), se o TC tem um jurisdicionado apenas, ou múltiplos. (SF) Sim e formal, sempre, pois há uma norma local que regulamenta (indicar a norma, se souber); (SI) Sim mas informal, sempre ou às vezes, pois é uma prática informal mas comum, dependendo do gestor e das motivações políticas em cada caso; (D) desconsidera o comando da LRF, o TC não exerce controle efetivo sobre esse tema; (n) Não, nunca; (-) Não sabe responder. 


\section{VARIAÇÕES NAS INTERPRETAÇÕES DOS TCS}

Os respondentes foram unânimes em dizer que a entrada em vigor da LRF melhorou efetivamente a atuação do Tribunal de Contas no controle dos jurisdicionados, divergindo apenas quanto à adoção das regras ser formal ou informal, conforme o caso, permitindo maior rapidez das decisões, controle concomitante e não só posterior, maior rigor nas análises técnicas e nas decisões do Pleno. Os aspectos onde o progresso não foi tão evidente foram a melhora de procedimentos de corregedoria e a ênfase em aspectos da macrogestão.

Na pesquisa atual, não foram identificados padrões diferentes de entendimentos da LRF entre regiões do País, o que era bastante comum nos primeiros anos de implantação, conforme experiência da autora. Com o passar do tempo, a necessidade de controlar e disponibilizar ao público grande quantidade de informações estimulou a informatização, integração e troca de experiências e de sistemas entre os TCs, que passaram a reproduzir métodos organizacionais. Isso pode ter aproximado as regiões norte, nordeste e centro-oeste dos métodos que foram pioneiramente desenvolvidos por TCs das regiões sul e sudeste.

Contudo, embora também não haja um padrão regional para a interpretação dos TCs, chama a atenção a falta de uniformidade de interpretação. Por um lado, dificilmente se encontra um TC que admita todas as exclusões das despesas com pessoal que poderiam ser feitas no cálculo dos limites; por outro lado, alguns TCs não admitem nenhuma exclusão de despesas desse limite. O modo como se materializa a interpretação também é diferente: uns adotam regras formais, tais como resoluções; outros passam a adotar regras informais, como leniência em julgamentos.

A interpretação e, portanto, a maior ou menor uniformidade entre os TCs, também varia ao longo do tempo. Três respondentes informaram que a exclusão de Imposto de Renda Retido na Fonte, que era aceita em anos anteriores, deixou de ser aceita e, em um caso, uma reincorporação gradual ao limite foi adotada. Uma possível explicação para a mudança de alguns entendimentos é a reação diferenciada às decisões do Promoex. Tal diferença de interpretação dos TCs foi objeto de reuniões do Promoex e a recomendação da maioria dos técnicos foi de que práticas que se distanciavam da LRF não fossem mais permitidas. Nem todos, porém, convergiram. Em estados onde tradicionalmente predominou a coalizão pró-gasto, com políticos articulados em oposição à LRF, o distanciamento da lei original parece ter sido maior.

\section{Limite de Despesas com pessoal/Receita Corrente Líquida}

Alguns respondentes admitiram que são realizadas as seguintes exclusões no cálculo de limite de pessoal não previstas na LRF: Imposto de Renda Retido na Fonte (normalmente deduzido do numerador e do denominador, em 4 casos), inativos (em 4 casos), pensionistas (em 3 casos) e espécies remuneratórias que são tratadas como se fossem indenizatórias (auxílios diversos, em 3 casos). Além disso, dois respondentes admitiram que o aporte atuarial para a previdência é utilizado para cobrir déficit financeiro quase imediatamente (em prazo inferior a 5 anos), o que significa que não deveria ser deduzido das despesas com pessoal, pois a LRF originalmente admite a exclusão do aporte atuarial, mas não do aporte financeiro.

Seis respondentes admitiram que o TC não coíbe efetivamente as situações de burla ao instituto constitucional do concurso público que encontra, o que pode indicar a burla de abrangência, quando parte das despesas é realizada "fora" do serviço público, em Organizações Sociais, por exemplo, ou com terceirizados que substituem servidores e empregados públicos, mas não são computados na despesa com pessoal. Neste caso, não há uma regra formal editada pelo TC, mas uma leniência com a prática, a qual se considera uma regra informal. Outra forma menos comum de relaxar o limite das despesas com pessoal é permitir que sejam adotados percentuais de limites de pessoal por poder diferentes da LRF (apenas um caso relatado).

Todas essas práticas são realizadas para relaxar os limites de gastos com pessoal de outros Poderes e também do próprio TC. Apenas em um caso foi admitida uma exclusão da Receita Corrente Líquida, por regra formal, possivelmente royalties ou transferências voluntárias, provocando intensificação dos limites. Em geral, a consequência é, portanto, a perda da efetividade das regras impostas pela LRF. A análise é consistente com Brasil (2016), que comparou os cálculos das despesas com pessoal dos estados, em percentual da Receita Corrente Líquida, pelos critérios adotados pelos TCs e pela regra formal da LRF. A diferença chega a 27,66\% no Mato Grosso do Sul, 21,07\% no Rio de Janeiro, 14,89\% no Distrito Federal e 12,51\% no Rio Grande do Sul, cujos técnicos não responderam ao questionário. 
A falta de transparência também é uma tônica recorrente. Também foram informados casos em que se permite que o regime de competência não seja utilizado para limites de pessoal ( $13^{\circ}$ salário, férias, etc.) ou que as despesas sejam reconhecidas apenas no exercício subsequente, inflando as "Despesas de Exercícios Anteriores" que são deduzidas para fins de apuração dos limites de pessoal. Além de distorcer a aplicação da legislação, o impacto pode ser defasado no tempo, reduzindo a transparência das contas públicas.

Durante as entrevistas foram relatados casos em que o TC aceita que não haja contabilização de reajustes e progressões funcionais devidos e contribuição patronal de inativos e pensionistas. Três técnicos admitiram que o TC permite que os órgãos jurisdicionados pratiquem o chamado "trem da alegria", que consiste na ascensão de servidores de nível médio para ocuparem, sem concurso público, cargos de nível superior, prática vedada pela Constituição Federal. Houve relatos dessa prática ocorrendo nos próprios TCs. O fato de ser este o aspecto central de divergência em relação à LRF é revelador, pois é justamente na contratação de pessoal que práticas patrimonialistas são exercidas e também é por meio das pessoas nomeadas nos próprios TCs que o poder é exercido.

\section{Limite de Dívida Consolidada Líquida/Receita Corrente Líquida}

Em relação à dívida, sempre houve menor número de exclusões para cálculo do limite e em menor frequência. Não surpreende que apenas um respondente tenha informado que o TC admite que ativos sem liquidez imediata sejam excluídos do cálculo da Dívida Consolidada Líquida, como se fossem disponibilidade de caixa. Um exemplo que ocorreu no passado foi a classificação da dívida ativa, de baixíssima liquidez e em parte irrecuperável, como disponibilidade de caixa. A consequência foi um relaxamento do Limite de Dívida Consolidada Líquida pela Receita Corrente Líquida. Porém, três respondentes informaram que o TC aceita que passivos não sejam contabilizados, fazendo com que deixe de ser evidenciada a situação da dívida e das operações de crédito. Nas entrevistas foram exemplificados a não contabilização de precatórios e de dívidas com concessionárias de energia e de contratos firmados, que são outras opções de relaxamento.

\section{Restos a pagar}

Há TCs que aceitam que, no final do mandato, os restos a pagar sejam superiores à disponibilidade de caixa "desde que no ano analisado a indisponibilidade não tenha se agravado em relação ao ano anterior" (dois casos informados). Há TCs que aceitam que, no final do mandato, os restos a pagar processados sejam cancelados para que seja cumprido artificialmente o limite ou que seja utilizada a disponibilidade de caixa do exercício seguinte (de janeiro, por exemplo) para calcular o limite dos restos a pagar (três e dois casos informados, respectivamente). Um dos respondentes informou que a disponibilidade de caixa do Estado é negativa, com anuência do Tribunal.

A finalidade dessa prática também seria evitar que as contas dos governadores e prefeitos fossem rejeitadas, embora, em um caso, tenha sido informado que "o Tribunal adota critérios diferentes para o Estado e os municípios”. O critério adotado para o Estado é menos rigoroso porque o vínculo da indicação política é com o governador. Outros TCs, porém, adotariam critérios igualmente flexíveis para ambos para não suscitarem questionamentos sobre a diferença de tratamento.

\section{Metas fiscais e orçamento}

Dos doze TCs pesquisados, em quatro casos os respondentes informaram que o TC admite que os fiscalizados não façam o contingencimento necessário para o cumprimento das metas fiscais, e em outros quatro casos, os respondentes informaram que não sabiam ou que o TC não exerce controle efetivo sobre esse tema. Isso significa que em mais da metade dos casos, há fraco controle sobre as metas fiscais. Em entrevista, um dos respondentes resumiu assim o quadro:

"Nos 17 anos de LRF, não houve nenhuma aplicação da multa prevista na Lei 10.028/00 e,
no entanto, o número de municípios que não cumprem a meta fiscal é enorme. (...) De forma
geral, a análise é efetuada verificando as contas isoladas da prefeitura, e se esta no ano
manteve equilíbrio orçamentário é aprovada. Pouco importa a consolidação e desequilíbrios
financeiros acumulados nos anos anteriores e sua redução".

As respostas abertas indicaram que ainda está longe de ocorrer o controle dos resultados fiscais, como propunha a LRF. Embora alguns indiquem que o controle é maior em relação a aspectos orçamentários, um dos respondentes informou que o TC admite que haja abertura de créditos adicionais sem autorização legislativa ou sem que seja cumprido limite legal para esse fim. Corroboram essa percepção os seguintes relatos: 


\begin{abstract}
"Às vezes a LOA não atende o art. 167, VII, CF. Embora haja registro na instrução das contas, a única "penalidade" é uma ressalva, com recomendação. Ano após ano. Também ocorre com os créditos abertos com recursos do superávit financeiro e de excesso de arrecadação que não são computados no limite de abertura dos créditos adicionais".

"A Conta Centralizadora não é segregada por fontes. É como se fosse um grande sacolão. Daí, o governo vai tirando, tirando, tirando...e, quando vê, aquele monte de nota de empenho sem dedução... negativo".
\end{abstract}

\title{
6 APLICAÇ̃̃O DO MODELO AO CASO LRF
}

A LRF é uma regra fiscal voltada para a solução de um problema de cooperação que gera gasto excessivo e sobre-endividamento. Além da lei em si, há regras informais constituídas por práticas e costumes aceitos, como, por exemplo, a interpretação da LRF pelos TCs, que podem gradualmente formalizar-se em resoluções, acórdãos e decisões que constituem a jurisprudência de um TC. No caso brasileiro, embora a jurisprudência de um TC esteja sujeita a alguma influência e imitação (isomorfismo), isso não implica subordinação de um Tribunal a outro, o que leva a diferentes formas de cálculo fiscal na Federação.

A questão é como e por que a LRF, aprovada em 2000, pode ter passado por mudanças em um processo histórico e quais os efeitos dessas mudanças. A aplicação da taxonomia de Mahoney e Thelen (2009) ao caso da LRF significa dizer que a criação da lei seria um exemplo de deslocamento (displacement), uma mudança em grande parte motivada por uma conjuntura desfavorável, com crises internacionais que colocaram em xeque a estabilidade macroeconômica no país. Apesar das tensões na negociação no Congresso Nacional, em virtude da intensa barganha política com governadores, é nos momentos de crise que "novas instituições e novos padrões devem ser construídos, no lugar dos antigos, que sucumbem" (Gourevitch, 1986).

As alterações legislativas da LRF, reintroduzindo, por exemplo, o refinanciamento de dívidas em contexto específico, seria o acréscimo em camadas (layering). Mais de 200 propostas de alteração da LRF haviam sido apresentadas no Congresso Nacional até $2010^{3}$. Não obstante, até 2013, apenas uma alteração havia sido aprovada e, ainda assim, para fortalecer o pilar de transparência da LRF (Lei Complementar $n^{\circ}$ 131/2009). A tentativa de acréscimo em camadas foi dificultada pelo menos até 2014, quando o início da grave crise econômica, a narrativa da coalizão pró-gasto e a pressão de governos estaduais impulsionaram a aprovação no Legislativo de novas regras flexibilizando a $\mathrm{LRF}^{4}$.

A aplicação da LRF com a chegada do Partido dos Trabalhadores ao poder e com a mudança do cenário externo após a crise de 2009 poderia ser descrita com um típico caso de deslizamento (drift). Na União, embora o Governo não tenha admitido o propósito de 'driblar' as regras da LRF, fez um ataque indireto ao negligenciar tais regras com operações heterodoxas (Nunes et al., 2017, p. 18). Estas operações culminaram na recomendação, pelo TCU, da rejeição das contas da Presidente, em 2014 e 2015, e no impeachment de Dilma Rousseff em 2016.

Diante da impossibilidade de alterar a LRF pela via legislativa, nos estados, a conversão foi pela interpretação a partir da relação simbiótica da LRF com os Tribunais de Contas, o que resultou em comportamentos que seriam indesejáveis na Federação, mas que atendiam às pressões políticas locais.

A implementação descentralizada da LRF permitiu alto nível de arbítrio no cumprimento da Lei, tendo em vista a autonomia dos TCs. Uma regra especificada de modo impreciso dá espaço para tal discricionariedade, embora esse não seja um requisito indispensável, tendo em vista que todas as regras são interpretadas. Assim, as diferentes interpretações e jurisprudências dos TCs que originaram a 'mutação genética' da LRF na Federação é um típico caso de conversão (conversion) em Mahoney e Thelen (2009).

É possível dizer que a LRF passou por todas as formas de mudança institucional do modelo, embora o foco aqui tenha sido a análise da conversão, porque "a mudança institucional ocorre com frequência quando os problemas de interpretação e aplicação de regras abrem espaço para que os atores implementem regras existentes de novas maneiras" (Mahoney \& Thelen, 2009, p. 4).

\footnotetext{
${ }^{3}$ Segundo levantamento da Consultoria de Orçamentos da Câmara dos Deputados, em 2010.

${ }^{4}$ Foram aprovadas propostas para permitir a alteração de índices nos contratos de refinanciamento das dívidas estaduais (Lei Complementar $n^{\circ}$ 148/2014, regulamentada pelo Decreto $n^{\circ} 8.616 / 2015$, alterada pela Lei Complementar $n^{\circ} 151 / 2015$, e Lei Complementar $n^{\circ} 156 / 2016$ ) e o refinanciamento das dívidas (Lei Complementar $n^{\circ}$ 159/2017). Além disso, a Lei Complementar $n^{\circ}$ 160/2017 afastou a necessidade de compensação nas novas renúncias de receita nos estados em casos específicos. Mais recentemente, foi aprovada a Lei Complementar $n^{\circ}$ 164/2018, para vedar a aplicação de sanções a município que ultrapasse o limite para a despesa total com pessoal nos casos de queda de receita em virtude da crise econômica.
} 
O principal conceito da LRF que tem sido interpretado de forma flexível é a despesa com pessoal. A finalidade, como disse um entrevistado, seria "atender interesses políticos dos governantes que os indicaram para os cargos", evitando que estes tenham contas rejeitadas, o que inviabilizaria suas "carreiras políticas, pelo enquadramento na Lei da Ficha Limpa”.

A interpretação da LRF pelos TCs está fortemente correlacionada com o critério de indicação política para o cargo de conselheiro pelos governadores dos estados. As diferentes interpretações podem estar associadas à redução da austeridade da legislação fiscal dada a natureza política dos conselheiros (Loureiro et al., 2009). Os TCs nem sempre estão dispostos a confrontar políticos eleitos que descumprem a lei. O grau com que confrontam pode diferir muito (Santiso, 2009), o que, consequentemente, leva a diferentes níveis de coerção em governos estaduais e municipais (Lino \& Aquino, 2018). Vários conselheiros são ex-políticos que têm estreito relacionamento com deputados estaduais. Então, também não há interesse em sancionar chefes do Poder Legislativo ou induzir cortes de pessoal nessas Casas.

Ainda, alguns respondentes informaram que há TCs que reinterpretam a LRF em benefício próprio, pois, caso fossem adotados os critérios originais, teriam que reduzir pessoal e "dispensar comissionados contratados também por afinidade política". Em um caso, foi informado que "não interessa comprar briga com o Judiciário", que também estaria desenquadrado aos limites da LRF, não fosse a interpretação mais flexível desde 2002. Tratase de referência indireta a processos contra alguns conselheiros que tramitam no Judiciário. Levantamento feito no Superior Tribunal de Justiça é revelador: quatro ministros do Tribunal de Contas da União e 37 conselheiros de TCs estaduais estão em investigação. O número equivale a 15\% dos 240 ocupantes destes cargos nos 34 TCs. Dos 37 conselheiros que respondem a 22 ações penais e 35 inquéritos, 14 teriam sido denunciados, 14 afastados e 11 delatados (Carvalho \& Schmitt, 2017).

A sustentação da regra fiscal provoca uma mudança da cultura ou da mentalidade coletiva, mas, ao mesmo tempo, depende dessa mentalidade para ser aceita e não rejeitada. As leis podem ser renegociadas continuamente e modificadas em sua redação (alterações legislativas), mas também na sua interpretação e implementação (como no caso das resoluções e acórdãos dos TCs). As mudanças nas regras formais do jogo político podem gerar mudanças institucionais na LRF, mas mudanças geradas pela introdução da LRF também podem ocasionar mudanças na política (Loureiro et al., 2009, p.1).

A implicação dessa mudança está em como a LRF deixa de ser uma expectativa de que algo efetivamente novo estava sendo implantado para todos governos em 2000, com expectativa de coerção para todos, para ser relaxada ao longo do tempo pelas interpretações dos TCs. A coerção de uma lei depende do quanto os agentes estão convencidos de que é necessário cumprir a regulação. No caso da LRF, por acreditarem que serão fiscalizados e sancionados, têm mais incentivos para cumpri-la. No entanto, se for consensual que é possível descumpri-la, influenciar ou subornar o aplicador da lei, a coerção será menor e a lei sem efeito.

A lei, como dito, opera ancorada e apoiada em um conjunto institucional anterior e pré-existente, sobretudo no caso em questão, na legislação que trata do Controle Externo e define a competência dos TCs, o que inclui a função de julgar contas de governos e aplicar sanções de forma autônoma. Porém, essa legislação também dá aos TCs espaço para terem suas próprias interpretações da LRF. Consequentemente, as eventuais interpretações diferentes dos 34 TCs podem em algum caso permitir que os governos a eles jurisdicionados gerenciem suas informações contábeis, orçamentárias e fiscais para jogar com a regra daquele Tribunal.

A relação simbiótica entre a LRF e as interpretações e proatividade dos TCs é mediada por organizações como a Secretaria do Tesouro Nacional, o Supremo Tribunal Federal e os governos locais. Essa mescla de expectativas e entendimentos é reforçada pelos prestadores de serviço de contabilidade e assessoria, pelos fornecedores de software de administração financeira e pelo próprio Controle Interno dos governos que acabam por assimilar tais regras "reinterpretadas", e as replicam em suas soluções e recomendações para garantir compliance dos governos locais ao entendimento dos TCs.

Por sua vez, a Secretaria do Tesouro Nacional, enquanto não criado o Conselho de Gestão Fiscal, guarda a competência de estabelecer normas de consolidação das contas públicas, além de aplicar a suspensão de operações de crédito, garantias e transferências voluntárias em caso de descumprimento da LRF. Nos primeiros anos da LRF, a falta de padrões nacionais contábeis e fiscais, bem como de um sistema centralizado para captura eletrônica de informação prejudicou a atuação da STN como protagonista da LRF. Ao mesmo tempo, os TCs implantavam seus sistemas de coleta de dados (Aquino et al., 2016), e difundiam aos seus jurisdicionados diferentes demandas para prestação de contas. Assim, à parte da emissão da consolidação das contas públicas no Balanço do Setor Público Nacional (BSPN), feita pela STN, o protagonismo da aplicação da LRF ficou com os TCs, reforçando a diversidade de interpretações na Federação. 


\section{CONCLUSÃO}

$\mathrm{O}$ artigo reúne evidências de que as assimetrias verificadas no cumprimento da LRF têm origem nas mudanças institucionais realizadas pelos TCs, pela via interpretativa. Isto porque, na forma federativa de Estado, os TCs não se subordinam uns aos outros e, como não há uma instância de cooperação e uniformização de interpretações, cada um atua como uma entidade jurisprudencial autônoma. Por um lado, a LRF impulsionou os TCs em relação à informatização e adoção de sistemas eletrônicos de coleta de dados de jurisdicionados, ao início de controle concomitante e não só posterior, e à uma melhoria nas análises técnicas. Por outro lado, a autonomia dos TCs trouxe diferentes interpretações da LRF e a dissonância nas regras fiscais em vigor nos diferentes estados da Federação.

Uma aplicação do modelo do Mahoney e Thelen (2009) mostra que, depois de entrar em vigor, a LRF continuou passando por mudanças institucionais e o caminho predominante de mudança, dentre os quatro descritos pelo modelo, foi a conversão, na qual as regras legais são formalmente as mesmas, mas a interpretação e o enforcement com que a LRF é aplicada mudam. No caso da interpretação da LRF, as mudanças e até o modo como se materializam são diferentes: ora por Resoluções dos TCs, ora por decisões em julgamentos que embutem elevado grau de discricionariedade. Assim, o fato de ser a conversão a forma de mudança institucional incremental acaba dando origem a uma mutação genética na Federação.

O questionário respondido por técnicos de 12 Tribunais de Contas identificou que o tema mais sujeito a interpretação e, portanto, se distanciando da essência original da LRF, é o limite de Despesas com pessoal/ Receita Corrente Líquida. A interpretação em geral relaxa o limite de gastos de pessoal, tanto para atender a interesses políticos dos governantes que indicaram os Conselheiros para os cargos, como para evitar exoneração de comissionados nos próprios TCs.

A falta de uniformidade nas interpretações e de transparência no cálculo dos indicadores, provocou uma proliferação de práticas de contabilidade criativa nos jurisdicionados, principalmente no cálculo da receita corrente líquida e da despesa com pessoal. A quase totalidade dessas práticas foi realizada para relaxar a LRF, gerando a perda da efetividade das regras impostas, tanto no que tange aos limites do Poder Executivo, evitando que as contas dos governadores e prefeitos fossem rejeitadas, como no que se refere ao limite dos demais Poderes e do próprio TC. É revelador que o rigor nos julgamentos tenda a ser maior nos municípios do que no estado porque o vínculo político neste último caso é também maior. Além disso, o fato de o limite das despesas com pessoal concentrar a maior parte das divergências parece estar associado às pressões pela manutenção de cargos e por aumentos de salário, também na esfera da influência política exercida.

O processo histórico de mudança da LRF, via interpretação e implementação pelos TCs, explica como as regras formais do jogo político podem ser alteradas pela introdução de uma nova instituição, mas também como a própria instituição pode passar por mudanças, não necessariamente legislativas, em virtude da atuação dos agentes no jogo político. Depois de 19 anos, a lei é outra, ou deu origem a várias outras aplicações da lei original, em virtude da característica de autonomia do modelo federativo.

A ausência de um padrão mínimo para atuação dos TCs e de uma corregedoria nacional pode estar mitigando a capacidade da LRF de prover solução para problemas de cooperação de geram gasto excessivo e sobre-endividamento. Mais do que o desenho das regras formais, a interpretação é determinante dos resultados. A estrutura federativa, tendo órgãos de auditoria operando no modelo napoleônico com excessiva autonomia operacional, pode ser um importante determinante para a limitação do alcance e efetividade das regras fiscais.

\section{REFERENCIAS}

Aquino, A. C. B. de., Azevedo, R. R. D., \& Lino, A. F. (2016). Isomorfismo, Tribunais de Contas e a automatização da coleta de dados de municípios. In: Anais do XVI Congresso USP de Controladoria e Contabilidade. São Paulo, SP, Brasil.

Aquino, A. C. B. de, \& Azevedo, R. R. D. (2017). Restos a pagar e a perda da credibilidade orçamentária. Revista de Administração Pública, 51(4), 580-595. DOI: http://dx.doi.org/10.1590/0034-7612163584

Azevedo, R. R., \& Lino, A. F. (2018). O distanciamento entre as Normas de Auditoria e as práticas nos Tribunais de Contas. Sociedade, Contabilidade e Gestão, 13(2), 9-27. DOI: https://doi.org/10.21446/scg_ufrj.v13i2.13665

Ayres, L., Kavanaugh, K., \& Knafl, K. A. (2003). Within-case and across-case approaches to qualitative data analysis. Qualitative health research, 13(6), 871-883. DOI: https://doi.org/10.1177/1049732303013006008 
Brasil (2016). Ministério da Fazenda. Secretaria do Tesouro Nacional. Boletim das Finanças Públicas dos Entes Subnacionais. Disponível em: <http://www.tesouro.fazenda.gov.br/documents/10180/0/Boletim+de+Finan cas $+\mathrm{P} \% \mathrm{C} 3 \%$ BAblicas + dos + Entes + Subnacionais/107970b4-9691-4263-a856-b37d655b42b2>. Acesso em: 11 abr. 2017.

Carvalho, C., \& Schmitt, G. (2017). TCU e TCEs têm 41 integrantes investigados. O Globo, 26/6/2017. Disponível em: https://oglobo.globo.com/brasil/tcu-tces-tem-41-integrantes-investigados-21518437. Acesso em $5 / 7 / 2017$.

Castro, A. L. B. D., \& Machado, C. V. (2012). A política federal de atenção básica à saúde no Brasil nos anos 2000. Physis: revista de saúde coletiva, 22, 477-506. DOI: http://dx.doi.org/10.1590/S0103-73312012000200005

Cruz, C. F., \& Afonso, L. E. (2018). Responsabilidade na Gestão Fiscal: um estudo em grandes municípios com base nos pilares da Lei de Responsabilidade Fiscal. Revista de Administração Pública, 52(1). DOI: http:// dx.doi.org/10.1590/0034-7612165847

Ferreira Júnior, S. (2006). As finanças públicas nos estados brasileiros: uma avaliação da execução orçamentária, no período de 1995 a 2004. Tese de Doutorado em Economia Aplicada. Universidade Federal de Viçosa.

Giambiagi, F.; Mora, M. (2007). Federalismo e endividamento subnacional: uma discussão sobre a sustentabilidade da dívida estadual. Revista de Economia Política, v. 27, p. 3. DOI: http://dx.doi.org/10.1590/S010131572007000300009

Gourevitch, Peter (1986). Politics in Hard Times - Comparative Responses to International Economic Crises. Ithaca and London. Cornell University Press.

Grin, E. J. (2014). Trajetória e avaliação dos programas federais brasileiros voltados a promover a eficiência administrativa e fiscal dos municípios. Revista de Administração Pública, 48(2), 459-480. DOI: http://dx.doi. org/10.1590/0034-76121399

Hidalgo, F. D., Canello, J., \& Oliveira, R. L. de (2016). Can politicians police themselves? Natural experimental evidence from Brazil's audit courts, Comparative Political Studies, v. 49, n. 13, p. 1739-1773. DOI: https:// doi.org/10.1177/0010414015626436

Lino, A. F., \& Aquino, A. C. B. D. (2018). A diversidade dos Tribunais de Contas regionais na auditoria de governos. Revista Contabilidade \& Finanças-USP, 29(76), 26-40. DOI: https://doi.org/10.1590/1808-057x201803640

Loureiro, M. R., Teixeira, M.A. C., \& Moraes, T. C. (2009). Democratização e reforma do Estado: o desenvolvimento institucional dos tribunais de contas no Brasil recente. Revista de Administração Pública, v. 43, n. 4.

Mahoney, J., \& Thelen, K. (2009). A Theory of Gradual Institutional Change, Explaining institutional change: ambiguity, agency, and power. Cambridge University Press.

Nunes, S. P. P., Nunes, R. C., \& Marcelino, G. (2017). O Regime Contábil nos Demonstrativos de Resultado Fiscal no Brasil: uma visão crítica. Anais do $3^{\circ}$ Congresso UnB de Contabilidade e Governança, Brasília, DF, Brasil.

Rodrigues, M. A. D. S. (2011) Conversão institucional na reforma da segurança pública no Brasil. Tese de Doutorado, Universidade de São Paulo.

Santiso, C. (2009). The political economy of government auditing: financial governance and the rule of law in Latin America and beyond. Routledge.

Santos, J. de C. (2005). Sustentabilidade fiscal dos estados e municípios de capitais no Brasil: uma análise com dados de painel para o período 1995-2004. 74 f. Dissertação (Mestrado em Economia) - Universidade de Brasília, Brasília.

\section{Como citar este artigo}

Nunes, S.P.P.; Marcelino, G.F. \& Silva, C.A.T. (2019). Os Tribunais de Contas na interpretação da Lei de Responsabilidade Fiscal. Revista de Contabilidade e Organizações, 13:e145151. DOI: http://dx.doi. org/10.11606/issn.1982-6486.rco.2019.145151 


\section{APÊNDICE A}

Cargo/Função:

Número de anos em que trabalha/trabalhou no Tribunal de Contas:

Formação (nível mais alto/área de conhecimento):

Parte A: Regras de composição e funcionamento dos Tribunais de Contas (respostas não utilizadas neste artigo).

\section{Parte B: Divergências na interpretação da $L R F$}

Para cada uma das perguntas 2 a 18, foi pedido que assinalem uma entre as seguintes alternativas: (i) Sim, sempre, pois há uma norma local que regulamenta (indicar a norma, se souber); (ii) Sim, sempre ou às vezes, pois é uma prática informal mas comum, dependendo do gestor e das motivações políticas em cada caso; (iii) Não, nunca; (iv) Eu não sei; (v) o Tribunal não exerce controle efetivo sobre esse tema.

Foi solicitado ainda que fosse indicado a data ou ano se soubesse, e a norma local que regulamente ao entendimento mencionado.

1) A entrada em vigor da LRF melhorou efetivamente a atuação do Tribunal de Contas no controle dos jurisdicionados? Se sim, especifique de que formas:

Informatização do Tribunal

Maior integração dos Tribunais de Contas, com troca de experiências

Aumento da disponibilização de informações ao público

Melhora de procedimentos de corregedoria

Aumento da rapidez das decisões

Controle concomitante e não só posterior

Ênfase em aspectos da macrogestão

Maior rigor nas análises técnicas

Maior rigor nas decisões do pleno

Outras. Quais?

2) O Tribunal de Contas admite exclusões da receita corrente líquida não expressamente previstas na LRF? Se sim ou às vezes, especifique quais:

IRRF

Despesa com pessoal relativa ao PSF

Despesa com pessoal relativa ao PACS

Fundo de pobreza

Transferências relativas a convênios

CIDE

Royalties

Fundos financeiro-fiscais que concedem incentivos (tributários ou creditícios) com recursos do ICMS

Outro. Qual?

3) O Tribunal de Contas admite que sejam adotados $\%$ de limites de pessoal por poder diferentes da LRF (por exemplo, a soma dos limites máximos por poder é maior que o limite máximo global)? 
4) O Tribunal de Contas admite exclusões das despesas com pessoal não expressamente previstas na LRF? Se sim ou às vezes, especifique quais:

Inativos

Pensionistas

Imposto de Renda Retido na Fonte-IRRF

Espécies remuneratórias (auxílios diversos), que não caracterizam de fato indenização

Outro. Qual?

5) O Tribunal de Contas admite que receitas e despesas previdenciárias de um poder sejam computadas em outro poder para fins de cálculo dos limites de pessoal?

6) O Tribunal de Contas admite que o aporte atuarial para a previdência seja utilizado para cobrir déficit financeiro quase imediatamente (em prazo inferior a 5 anos)?

7) O Tribunal coíbe efetivamente as situações de burla ao instituto constitucional do concurso público que encontra ("consultorias" e terceirização que substitui servidores e empregados públicos, por exemplo)?

8) O Tribunal de Contas admite que os órgãos jurisdicionados, inclusive suas unidades administrativas, promovam atos de provimento derivado decorrente da alteração dos atributos dos componentes do sistema remuneratório previsto no artigo 39, $\S 1^{\circ}$ da Constituição Federal ('trem da alegria')?

9) O Tribunal de Contas admite que o regime de competência não seja utilizado para cômputo de limites de pessoal ( $13^{\circ}$ salário, férias, etc.)?

10) O Tribunal de Contas admite que haja abertura de créditos adicionais sem autorização legislativa ou sem que seja cumprido limite legal para esse fim?

11) O Tribunal de Contas admite que os fiscalizados não façam o contingencimento necessário para o cumprimento das metas fiscais?

12) O Tribunal de Contas admite que o regime de competência não seja utilizado em despesas de forma geral, inflando as "Despesas de Exercícios Anteriores"?

13) O Tribunal de Contas admite que sejam excluídas no cálculo da Dívida Consolidada Líquida parcelas que não tem liquidez imediata (dívida ativa, por exemplo)?

14) O Tribunal de Contas admite que passivos não sejam contabilizados, fazendo com que deixe de ser evidenciada a situação da dívida e das operações de crédito? Em caso positivo, especifique quais:

Precatórios

Passivo atuarial do RPPS

Outro. Qual?

15) O Tribunal de Contas aceita que, no final do mandato, os Restos a Pagar sejam superiores à disponibilidade de caixa?

16) O Tribunal de Contas aceita que, no final do mandato, os Restos a Pagar processados sejam cancelados para que seja cumprido o limite de restos a pagar?

17) O Tribunal de Contas admite que seja utilizada a disponibilidade de caixa do exercício seguinte (de janeiro, por exemplo) para calcular o limite dos restos a pagar?

18) O Tribunal de Contas admite que os fiscalizados não coloquem as informações exigidas pela LRF em portal de transparência? 